\title{
A study of the mortality of Cornish tin miners
}

\author{
A J FOX, ${ }^{*}$ P GOLDBLATT, AND L J KINLEN $\dagger$ \\ From the Medical Statistics Division, Office of Population Censuses and Surveys, London, UK
}

\begin{abstract}
Increased mortality from cancer of the lung has been found in several studies of miners exposed to high levels of radioactivity in underground air. In view of their exposure to raised levels of radiation, we have studied the mortality of a group of men recorded as Cornish tin miners in 1939. Using occupational description, a crude classification of exposure was derived for these miners. The meaningfulness of this classification was supported by differences in mortality from silicosis and silicotuberculosis. A twofold excess of cancer of the lung was found for underground miners, while for other categories mortality from this cause was less than expected. This supports the findings of previous studies on exposure to radon and its daughters. An excess of cancer of the stomach was also observed among underground miners.
\end{abstract}

Metalliferous miners exposed to high levels of radioactivity, such as uranium miners in Colorado ${ }^{1}$ and Czechoslovakia $^{2}$ and Newfoundland fluorspar miners, ${ }^{3}$ have been shown to have increased mortality from lung cancer. The only British study of such a group concerns haematite miners in Cumberland. ${ }^{4}$ As high levels of radon and its daughters have been consistently recorded in tin mines in Cornwall, these studies suggested that it would be useful to look at the health of men working in these mines.

Although the National Radiological Protection Board (NRPB) recently established a National Register of Radiation Workers to monitor possible radiation-linked effects, ${ }^{56}$ this register did not include records of tin miners. We therefore looked for alternative ways of conducting a study. National Health Service Central Register (NHSCR) records enabled the Office of Population Censuses and Surveys (OPCS) to describe the subsequent mortality of individuals who were registered in 1939.7 These records include area of residence and occupation in 1939 , and have been used as the basis of a study.

\section{Methods}

NHSCR records for two tin mining areas in Cornwall-namely, Cambourne and Redruth UD and St Just UD-were searched for men whose occupational description in 1939 included mention of tin

*Now holds SSRC professorial fellowship in social statistics at City University.

†Cancer Research Campaign Gibb Fellow.

Received 6 August 1980

Accepted 10 September 1980 mining. For each tin miner identified, including those described as retired, information concerning job description was extracted together with date of birth and, where relevant, dates of death and of any periods during which death details would not be notified to NHSCR. The latter include dates of entry to the armed Services or emigration. In the case of deaths the death certificate was obtained and then cause coded by OPCS staff according to the rules of the 8th Revision of the International Classification of Disease (ICD).

On the basis of occupational description, the men in each of the two areas were separated into underground and surface miners. Those whose occupation was inadequately described for this purpose formed a third category. Man-years-at-risk were calculated for each five-year calendar period and for each ten-year age group from October 1939 to the end of 1976 or to the date of death or emigration, if earlier. Expected numbers of deaths attributed to each cause analysed were obtained by multiplying the man-years-at-risk in each age group and in each calendar period by corresponding mortality rates for England and Wales. Appropriate rates were derived from published annual figures by conversion of all codes to 8 th revision equivalents.

\section{Results}

The study population consisted of 1333 tin miners, who contributed a total of 27631 man-years-at-risk. Three-quarters of them lived in one of the two areas studied. Considerable differences in 1939 were noted in the age and occupational distribution of miners in 
the two areas. The larger population was older $(14.5 \%$ aged 65 or over compared to $6.2 \%)$ and contained fewer men classified as underground $(20.7 \%)$ or unspecified $(38 \%)$ miners than the other $(33.2 \%$ and $49.4 \%$ respectively). This age difference between areas was observed in all three occupational categories.

In each area the proportion of men aged 65 or over was smallest among underground miners $(4.9 \%$ and $1.1 \%$ ); it was highest for unspecified miners $(18.7 \%$ and $8.9 \%)$. Overall, $12.5 \%$ of men were aged 65 or over in 1939, and consequently a large proportion of man-years were experienced in the earlier years of the study.

Observed and expected numbers of deaths and standardised mortality ratios (SMRs) from major causes for the period October 1939 to December 1976 among the whole study population are shown in table 1 . Overall mortality was significantly raised (SMR 122). The largest SMR, 160, based on 185 deaths, was for respiratory diseases. This excess is explained by 93 deaths from silicosis. In addition, there were 56 deaths from silicotuberculosis, which ICD rules categorise separately under "infective and parasitic diseases." Excess mortality was also recorded for lung cancer (SMR 117) and stomach cancer (SMR 141).

When the causes of death are analysed in relation to occupation, as in table 2 , mortality from respiratory diseases and silicotuberculosis (combined) is highest among underground workers (SMR 473) and least among surface workers (SMR 76), as would be expected if the occupational categories reflected differences in exposure to dust. Mortality from lung and stomach cancers also appears to be exposure-related; among underground workers the SMR for lung cancer was 211 and for stomach cancer 200, compared with 74 and 106, respectively,
Table 1 Observed and expected numbers of deaths by major causes and standardised mortality ratios (SMR) among Cornish tin miners (1939-76)

\begin{tabular}{lccc}
\hline Cause of death (8th Rev ICD codes) & Observed & Expected & SMR \\
\hline All neoplasms (140-239) & 171 & $147 \cdot 7$ & 116 \\
Lung cancer (162) & 61 & $52 \cdot 0$ & 117 \\
Stomach cancer (151) & 33 & $23 \cdot 4$ & 141 \\
Other cancers & $77^{*}$ & $72 \cdot 3$ & 107 \\
Circulatory diseases (390-458) & 378 & $380 \cdot 7$ & 99 \\
Respiratory diseases (460-519) & 185 & $115 \cdot 7$ & 160 \\
Silicosis (515) & 93 & 0 & - \\
Other respiracory diseases & 92 & $115 \cdot 7$ & 80 \\
Accidents (800-999) & 28 & $25 \cdot 4$ & 110 \\
Silicotuberculosis (010) & 56 & 0 & -11 \\
Other causes & 118 & $99 \cdot 3$ & 119 \\
All causes & $936 \dagger$ & $768 \cdot 8$ & 122 \\
\hline
\end{tabular}

* Of the following sites and types: buccal cavity and pharynx (7); oesophagus (7); colon (11); rectum (10); pancreas and biliary tract (7); prostate (8); other genitourinary (5); leukaemia (5); and other and unspecified neoplasms (17).

$\dagger$ This figure excludes two deaths of men who had not re-registered at NHSCR after emigration. One of these deaths was due to accidental causes, the other to cancer of the lung.

among the surface miners. Mortality among underground miners was high for silicosis and for lung and stomach cancers in each of the calendar periods 1939-50, 1951-60, 1961-70, and 1971-6.

\section{Discussion}

This study confirms high silicosis-related mortality among Cornish tin miners. ${ }^{8}$ Besides the 93 deaths recorded from this cause there were, among the 936 deaths recorded in this study, an additional 56 deaths attributed to silicotuberculosis. The much higher proportion of deaths from silicosis among underground than among surface workers would be consistent with the greater exposure to dust of the former group. Since mortality from these causes of death by occupational category reflects known exposure-related differences we may assume that the

Table 2 Mortality of Cornish tin miners by cause and occupation

\begin{tabular}{|c|c|c|c|c|c|c|}
\hline \multirow[t]{3}{*}{ Cause of death } & \multicolumn{6}{|c|}{ Occupation } \\
\hline & \multicolumn{2}{|c|}{ Underground } & \multicolumn{2}{|c|}{ Inadequately described $\dagger$} & \multicolumn{2}{|c|}{ Surface } \\
\hline & $S M R$ & (Deaths) & $S M R$ & (Deaths) & $S M R$ & (Deaths) \\
\hline Cancer & 189 & $(63)$ & 102 & (63) & 86 & (45) \\
\hline Lung & 211 & (28) & 94 & (20) & 74 & (13) \\
\hline Stomach & 200 & (10) & 143 & (14) & 106 & (9) \\
\hline Other & 160 & $(25)$ & 95 & (29) & 86 & (23) \\
\hline Respiratory diseases and silicotuberculosis & 473 & (104) & 209 & (103) & 76 & (34) \\
\hline Silicotuberculosis & $*$ & (31) & $*$ & (22) & $*$ & (3) \\
\hline Silicosis & $*$ & (44) & $*$ & (42) & $*$ & (7) \\
\hline Other respiratory & 132 & (29) & 79 & (39) & 54 & $(24)$ \\
\hline Accidents & 159 & (10) & 124 & (13) & 58 & (5) \\
\hline Other causes & 111 & (99) & 104 & $(215)$ & 98 & $(182)$ \\
\hline All causes & 183 & (276) & 120 & (394) & 92 & (266) \\
\hline
\end{tabular}

* Not applicable.

†Presumably includes both underground and surface workers. 
descriptions "underground" and "surface" in these data represent a meaningful exposure measure.

This study points to an excess of lung cancer among underground miners but not among surface workers. Although smoking habits were not available, this exposure-related excess was unlikely to be attributable to differences in smoking; there is evidence ${ }^{10}$ that because of restriction in smoking at work, below-ground miners smoke less than those working above ground.

The twofold increase in this study probably reflects raised levels of radon reported from tin mines in Cornwall. Increased mortality from lung cancer has been reported in several other groups of miners exposed to raised levels of radon daughters in underground air. These include uranium miners in Czechoslovakia ${ }^{2}$ and Colorado, USA, ${ }^{1}$ as well as Newfoundland fluorspar miners ${ }^{3}$ and metal miners in Sweden. ${ }^{11}$ Excess lung cancer has been recorded among Cumberland haematite miners, where there are also raised levels of radon daughters. In the latter case, however, the excess may possibly be partly due to iron ore itself. 4

Levels of radon daughters that may have influenced mortality reported here are mainly those to which miners were exposed before the war. The earliest known measurements, however, were those carried out by NRPB in 1967-8. These indicated average working levels of 3.4 and 1.2 in the two principal mines in the areas covered by this study (NRPB, personal communication). The recommended standard for men exposed to radon in underground air is one working level month (WLM); this is calculated by multiplying months of exposure per year by working levels. NRPB estimate exposure rates for these two mines of 25 WLM and 15 WLM respectively (personal communication).

Although the SMR for lung cancer among underground miners was higher ( 282 based on 11 deaths) in the area containing the mines with higher levels of radon daughters in 1967-8 than in the other area (SMR of 183 based on 17 deaths), the difference was not statistically significant.

Increased mortality from stomach cancer was also noted in this study. Occupational differences were evident in that this excess was greatest in underground miners and least in surface workers (table 2). These data are consistent with two previously suggested hypotheses. One is that men engaged in more strenuous work have higher rates of stomach cancer; ${ }^{12}$ the other is that stomach cancer is related to exposure to dust. ${ }^{101314}$
NHSCR records do not include detailed employment histories. The Medical Research Council, however, in an earlier study of a mine included here collected such records (J Boyd, personal communication). These have been made available to us and, by integrating the records of the two studies, we intend to investigate the relation between mortality and duration of exposure. The present finding of an excess of lung cancer among underground tin miners may largely reflect exposure many years ago. In recent years reductions in the levels of radon daughters have repeatedly followed improvements in ventilation. ${ }^{15}$ Raised levels of radon daughters, however, continue to be recorded, and studies of men with more recent exposure are required to evaluate any continuing hazard.

\section{References}

${ }^{1}$ Wagoner JK, Miller RW, Lundin FE, Fraumeni JF, Haij ME. Unusual cancer mortality among a group of underground metal miners. $N$ Engl J Med 1963;269: 284-9.

${ }^{2}$ Sevc J, Kunz E, Placek V. Lung cancer in uranium miners and long-term exposure to radon daughter products. Health Phys 1976;30:433-7.

${ }^{3}$ de Villiers AJ, Windish JP. Lung cancer in a fluorspar mining community. Br J Ind Med 1964;21:94-109.

${ }^{4}$ Boyd JT, Doll R, Faulds JS, Leiper T. Cancer of the lungs in iron ore (haematite) miners. Br J Ind Med 1970;27: 97-105.

${ }^{5}$ National Radiological Protection Board Bulletin 1978 June: 3. (No 22.)

- National Radiological Protection Board Bulletin 1978 July: 29. (No 24.)

${ }^{7}$ Fox $J$. The role of OPCS in occupational epidemiology: some examples. Ann Occup Hyg 1979;21:393-403.

${ }^{8}$ Haldane JS, Martin JS, Thomas RA. Report on the health of Cornish miners. Cmn 2091. London: HMSO, 1904.

${ }^{9}$ Garrad J. Vital capacity measurements in Cornish tin miners. Br J Ind Med 1949;6:221-9.

10 Office of Population Censuses and Surveys. Occupational mortality. The Registrar General's decennial supplement for England and Wales, 1970-72. (Series DS No 1.) London: HMSO, 1978.

${ }^{11}$ Axelson $\mathrm{O}$, Sundell $\mathrm{L}$. Mining, lung cancer and smoking. Scand J Work Environ Health 1978;4:46-52.

12 Stukonis M, Doll R. Gastric cancer in man on physical activity at work. Int J Cancer 1969;4:248-54.

${ }^{13}$ Stocks P. On the relations between atmospheric pollution in urban-rural localities and mortality from cancer, bronchitis and pneumoconiosis. Br J Cancer 1960;14: 397-418.

14 Jacobsen M. Dust exposure, lung diseases and coal miners' mortality. Edinburgh: 1976. (Ph D thesis.)

${ }^{15}$ Strong JC, Laidlaw AJ, O'Riordan MC. Radon and its daughters in various British mines. National Radiological Protection Board, 1975. (NRPB-R39.) 